\title{
Hemophagocytic lymphohistiocytosis in a patient with human immunodeficiency virus infection: A case report
}

\author{
YIJUN NIE $^{1}$, ZHANGLIN ZHANG $^{1}$, HONG WU $^{2}$ and LAGEN WAN ${ }^{1}$ \\ ${ }^{1}$ Department of Clinical Laboratory, First Affiliated Hospital of Nanchang University, Nanchang, Jiangxi 330006; \\ ${ }^{2}$ Institute of Blood Transfusion, Jiangxi Province Blood Center, Nanchang, Jiangxi 330052, P.R. China
}

Received August 21, 2015; Accepted January 26, 2017

DOI: 10.3892/etm.2017.4241

\begin{abstract}
Hemophagocytic lymphohistiocytosis (HLH), also termed hemophagocytic syndrome, is a severe, life-threatening inflammatory condition that results from an excessive, prolonged and ineffective immune response. The syndrome occurs due to overactive macrophages from the bone marrow or lymph tissue that phagocytose erythrocytes leukocytes and platelets. HLH in a patient with human immunodeficiency virus infection has rarely been studied. The present case study described an uncommon case of this syndrome in combination with human immunodeficiency virus infection in a patient, who eventually succumbed to severe infection and multiple organ failure following the refusal of medical treatment.
\end{abstract}

\section{Introduction}

Hemophagocytic lymphohistiocytosis (HLH), also termed hemophagocytic syndrome, is a state of severe, life-threatening inflammation caused by an extreme, prolonged and ineffective immune response (1). HLH may occur as a genetic or sporadic disorder and, though seen as an inherited condition affecting primarily a pediatric population, HLH may occur at any age. Furthermore, HLH may be encountered in association with a variety of underlying diseases and is considered a hyperinflammatory syndrome with high mortality, even with appropriate treatment $(1,2)$. The syndrome is typically induced by overactive macrophages from the bone marrow or lymph tissue, which phagocytose erythrocytes, leukocytes and platelets $(3,4)$. The clinical characteristics of HLH include

Correspondence to: Ms. Hong Wu, Institute of Blood Transfusion, Jiangxi Province Blood Center, 1900 Jinsha Road, Nanchang, Jiangxi 330052, P.R. China

E-mail:wuhong0918@163.com

Mr. Lagen Wan, Department of Clinical Laboratory, First Affiliated Hospital of Nanchang University, 17 Yongwaizheng Street, Nanchang, Jiangxi 330006, P.R. China

E-mail: 564604485@qq.com

Key words: hemophagocytic lymphohistiocytosis, human immunodeficiency virus infection, multiple organ failure fever for an extended duration, hepatosplenomegaly, cytopenia and hemophagocytosis due to activated macrophages. HLH may be classified as either primary familial HLH, where the cause is predominantly genetic, or secondary HLH, which is typically attributed to infections. More commonly, viral infections such as Epstein-Barr virus (EBV) may trigger secondary HLH; however, autoimmune diseases and malignancies have also been demonstrated to have a role in secondary HLH (5). Previous reports of HLH have focused on children and malignancy-related diseases $(6,7)$. HLH in a patient with human immunodeficiency virus (HIV) infection has rarely been investigated previously (8). The present study demonstrates an uncommon case of HLH in combination with HIV infection in a patient, who eventually succumbed to severe infection and multiple organ failure following refusal of medical treatment.

\section{Case report}

General information and medical examination. In May 2015, a 42-year-old male presented to the First Affiliated Hospital of Nanchang University (Nanchang, China) with a medical history of high fever experienced for 30 days and sudden breathing difficulty for 1 day. The family of the patient complained that 1 month ago, without apparent inducement, he developed recurrent fever, headache, dizziness, nausea, vomiting, chest tightness and shortness of breath. The patient was admitted to a local county-level hospital and given anti-infection and anti-flu treatment (specific drug use is unknown). The patient experienced recurrence of high fever for 4-5 days after an initial improvement in fever symptoms for 2-3 days. This fluctuation in fever symptoms persisted for several weeks.

Routine blood examination and bone marrow smears were performed to rule out infectious diseases. The complete blood count indicated pancytopenia: White blood cell count, $0.30 \times 10^{9} / 1$ (normal range, $4-10 \times 10^{9} / 1$ ); red blood cell count, $3.22 \times 10^{12} / 1$ (normal range, 4.09-5.71 $\times 10^{12} / 1$ ); hemoglobin levels, $81 \mathrm{~g} / 1$ (normal range, 131-172 g/l); and platelet count, $29 \times 10^{9} / 1$ (normal range, $\left.85-300 \times 10^{9} / 1\right)$. Furthermore, increased levels of serum ferritin were exhibited $(>2,000.0 \mu \mathrm{g} / \mathrm{l}$; normal range, 30-400 $\mu \mathrm{g} / \mathrm{l})$ and soluble interleukin-2 receptor levels were increased $(44,000 \mathrm{pg} / \mathrm{ml}$; normal levels, $<6,400 \mathrm{pg} / \mathrm{ml})$. Additional laboratory findings were as follows: White blood cell count, $0.30 \times 10^{9} / 1$ with $20.1 \%$ neutrophils, $53.3 \%$ lymphocytes and $23.3 \%$ monocytes; aspartate aminotransferase (AST), 
Table I. Routine blood examination results on each day of hospitalization.

\begin{tabular}{|c|c|c|c|}
\hline Variable & $\begin{array}{l}\text { First } \\
\text { day }\end{array}$ & $\begin{array}{c}\text { Second } \\
\text { day }\end{array}$ & $\begin{array}{c}\text { Third } \\
\text { day }\end{array}$ \\
\hline White blood cell $\left(\mathrm{x} 10^{9} / 1\right)$ & 0.30 & 0.44 & 0.40 \\
\hline Neutrophils (\%) & 20.1 & 20.4 & 17.6 \\
\hline Lymphocytes (\%) & 53.3 & 61.4 & 52.5 \\
\hline Monocytes (\%) & 23.3 & 18.2 & 16.8 \\
\hline Red blood cells (x 10 $12 / 1)$ & 3.22 & 3.14 & 2.74 \\
\hline Hemoglobin (g/l) & 81 & 78 & 70 \\
\hline Platelets $\left(\times 10^{9} / 1\right)$ & 29 & 19 & 13 \\
\hline Alanine aminotransferase (U/l) & 130 & 147 & 169 \\
\hline Aspartate aminotransferase (U/1) & 721 & 762 & 943 \\
\hline Total protein $(\mathrm{g} / \mathrm{l})$ & 55.2 & 42.3 & 38.5 \\
\hline Albumin (g/l) & 21.2 & 20.5 & 19.5 \\
\hline Globulin (g/l) & 34.0 & 21.8 & 19.0 \\
\hline Ratio of albumin to globulin & 0.62 & 0.94 & 1.03 \\
\hline$\gamma$-glutamyltranspeptidase (U/l) & 191 & 156 & 122 \\
\hline Creatinine (mmol/l) & 77.7 & 293.0 & 285.7 \\
\hline Urea $(\mu \mathrm{mol} / \mathrm{l})$ & 4.2 & 7.5 & 10.3 \\
\hline Uric acid $(\mu \mathrm{mol} / \mathrm{l})$ & 118 & 255 & 248 \\
\hline Creatine kinase (U/1) & - & 199 & 573 \\
\hline Amylase (U/l) & - & 116 & 123 \\
\hline Plasma endotoxin $(\mathrm{U} / \mathrm{ml})$ & 1.23 & 3.06 & 23.58 \\
\hline
\end{tabular}

$721 \mathrm{U} / 1$; alanine aminotransferase (ALT), $130 \mathrm{U} / 1$; lactate dehydrogenase, $963 \mathrm{mg} / \mathrm{dl}$; alkaline phosphatase, $235 \mathrm{U} / \mathrm{l}$; and $\gamma$-glutamyltranspeptidase, $191 \mathrm{U} / 1$. A reduced level of total protein was observed (55.2 g/l; normal range, 60-78 g/l), albumin was $21.2 \mathrm{~g} / \mathrm{l}$ (normal range 34-48 g/l) and there was an increased level of C-reactive protein $(94.60 \mathrm{mg} / \mathrm{l}$; normal range, $0-8 \mathrm{mg} / \mathrm{l})$. D-Dimer levels were high $(6,779 \mu \mathrm{g} / \mathrm{l}$; normal range, $0-300 \mu \mathrm{g} / 1)$. Serum antibody to $\mathrm{EBV}$, tubercle bacillus and hemococcidium were negative.

The results of computed tomography imaging examination of the upper abdomen indicated infection in both lungs, fatty liver, splenomegaly and retroperitoneal multiple enlarged lymph nodes. The findings indicated a preliminary diagnosis of infectious multiple organ dysfunction syndrome, pulmonary infection, and hypoproteinemia.

Results of bone marrow and peripheral blood smear. Bone marrow fluid was obtained by bone marrow aspiration. A bone marrow smear and peripheral blood smear was performed using Wright and Giemsa staining (Baso 4017 kit; Baso Diagnostics Inc., Zhuhai, China). Both samples were observed under a microscope (ECLIPSE Ci; Nikon Corp., Tokyo, Japan) with a magnification of $x 1,000$. Karyocyte cells in the bone marrow were decreased slightly and the proportion of lymphocytes was high $(46 \%$; normal range, $<20 \%$ ). The proportion of granulocyte and erythrocytes was borderline normal; however, the mature stage of the granulocyte was markedly decreased. Macrophages were exhibited at an elevated percentage of $8.5 \%$ and hemophagocytosis was clearly observed. Cellular
A
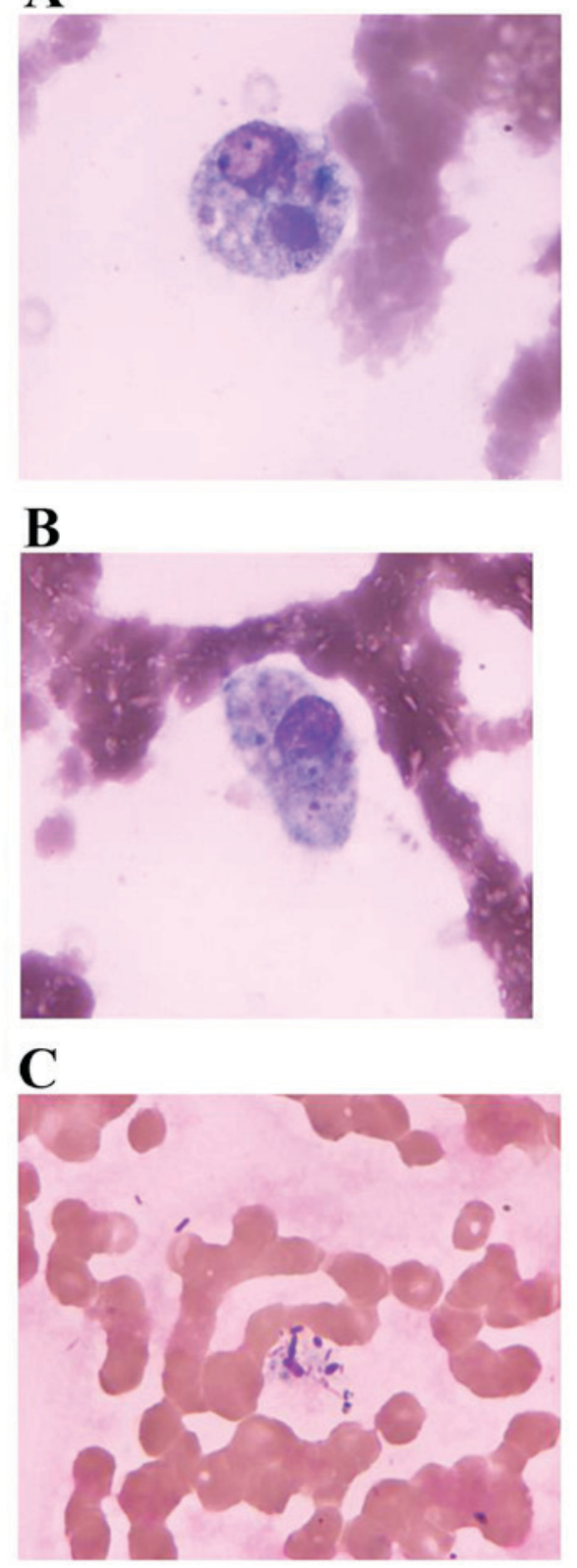

Figure 1. (A and B) Bone marrow aspirate smear and $(\mathrm{C})$ peripheral blood smear demonstrated phagocytosis of macrophages, which were irregular in shape, leading to the diagnosis of hemophagocytic lymphohistiocytosis (Wright and Giemsa staining; magnification, x1,000).

size of the macrophages ranged between 20 and $55 \mu \mathrm{m}$ in diameter and their shapes were rounded and irregular with irregular margins accompanying pseudopodia. The macrophage possessed abundant cytoplasm, indicated as grey blue or light grey, which engulfed a complete blood cell and fungi or other unknown microbes (Fig. 1A and B). These macrophages often exhibited single eccentric nuclei and possessed a rounded or oval nucleus and loose mesh nuclear chromatin. The morphology and classification of white blood cells in the peripheral blood were not abnormal and the distribution of fungi and bacteria was observed in the cytoplasm (Fig. 1C).

Disease progression and HIV diagnosis. The patient was hospitalized for three days and treated with anti-infection 
and anti-flu treatment (specific agents unknown). The levels of peripheral blood hemoglobin, percentage of monocyte cells and platelets decreased and the serum total protein and albumin levels gradually declined over the course of these three days. Furthermore, ALT, AST, urea, creatinine and plasma endotoxin levels were rapidly increased (Table I). On the third day of hospitalization, the patient appeared delirious, moist rales were heard in both lungs and multiple organ failure and scattered ecchymosis were exhibited. The predominant concern was the multiple organ failure, acute respiratory failure, acute liver failure, blood coagulation disorder, pulmonary infection and AIDS. Blood specimens were screened for AIDS and sent for examination to the Center for Disease Control of Jiangxi Province (CDC) to confirm the patient was infected with HIV. Following three days, the HIV test from CDC confirmed a positive diagnosis. The patient's family refused medical treatment on the third day of hospitalization. The patient subsequently succumbed to infectious multiple organ failure in his home.

\section{Discussion}

Fever, cytopenia of at least two cell types, hypertriglyceridemia and/or hypofibrinogenemia, hyperferritinemia (>500 $\mu \mathrm{g} / \mathrm{l})$, hemophagocytosis, elevated levels of serum CD25, decreased levels of NK cell activity and splenomegaly are a set of symptoms, of which five are required to suggest secondary HLH, according to the guidelines of the International Histiocyte Society (9). Based on the clinical and laboratory findings of fever, splenomegaly, cytopenias, hemophagocytosis in the bone marrow, hyperferritinemia and raised serum CD25 levels, a diagnosis of secondary HLH was therefore established.

The association between HLH and HIV is not well understood, as few such cases exist. HIV infection may contribute to the development of HLH, possibly through mechanisms related to $\mathrm{CD} 4^{+}$cells (predominantly $\mathrm{T}$ lymphocytes, monocytes, macrophages and dendritic cells) (10). Following HIV infection, viral incorporation of $\mathrm{CD}^{+}$cell DNA, combined with an overwhelming trophic response of relapsed $\mathrm{T}$ cell lymphoma may overstimulate the immune system, leading to HLH (11). At present, the pathogenesis of HLH has been suggested to be associated with a deficiency in cytolytic activity, which results from stimulation of lymphocytes and histiocytes (12). This uncontrolled immune response causes enhanced production of pro-inflammatory cytokines and major histocompatibility complex I and II molecules from macrophages as well as the expansion of inflammatory monocytes. Subsequently, this heightened inflammatory response causes necrosis, organ failure and promotes the proliferation and phagocytic activity of histiocytes (13). In the present case, the macrophages appeared to exhibit hyperactivity, which was indicated by the markedly elevated percentage of monocytes detected in the peripheral blood and the markedly increased percentage of macrophages detected in the bone marrow. Furthermore, hemophagocytosis in macrophages was clearly observed from the bone marrow and peripheral blood smear.
HLH is difficult to treat and is typically associated with a high morbidity and mortality rate $(3,14)$. HLH therapy must target the suppression the hyper-stimulated immune system via abolishing activated $\mathrm{CD} 8^{+} \mathrm{T}$ lymphocytes or macrophages, in addition to treating any existing HLH triggers, including infections, autoimmune diseases and malignancies (14).

The present case study demonstrates that HLH associated with HIV infection is a severe disease with a poor prognosis and may result in infection, multiple organ failure and mortality if the correct treatment is not administered in a timely-manner. In the present case, laboratory testing, including cell morphological examination and hemophagocytosis detected in the bone marrow, indicated that HLH was associated with HIV infection. Therefore, laboratory physicians should consider HLH and identify the possible cause (infections, autoimmune disease and malignancies) once intense hemophagocytosis is detected in the bone marrow.

\section{References}

1. Janka GE and Lehmberg K: Hemophagocytic lymphohistiocytosis: Pathogenesis and treatment. Hematology Am Soc Hematol Educ Program 2013: 605-611, 2013.

2. Campo M and Berliner N: Hemophagocytic Lymphohistiocytosis in adults. Hematol Oncol Clin North Am 29: 915-925, 2015.

3. Henter JI, Horne A, Aricó M, Egeler RM, Filipovich AH, Imashuku S, Ladisch S, McClain K, Webb D, Winiarski J and Janka G: HLH-2004: Diagnostic and therapeutic guidelines for hemophagocytic lymphohistiocytosis. Pediatr Blood Cancer 48: 124-131, 2007.

4. Janka GE and Lehmberg K: Hemophagocytic syndromes-an update. Blood Rev 28: 135-142, 2014.

5. Malinowska I, Machaczka M, Popko K, Siwicka A, Salamonowicz M and Nasiłowska-Adamska B: Hemophagocytic syndrome in children and adults. Arch Immunol Ther Exp (Warsz) 62: 385-394, 2014.

6. Lehmberg K, Albert MH, Beier R, Beutel K, Gruhn B, Kröger N, Meisel R, Schulz A, Stachel D, Woessmann W, et al: Treosulfan-based conditioning regimen for children and adolescents with hemophagocytic lymphohistiocytosis. Haematologica 99: 180-184, 2014.

7. Lehmberg K, Nichols KE, Henter JI, Girschikofsky M, Greenwood T, Jordan M, Kumar A, Minkov M, La Rosée P, Weitzman S, et al: Consensus recommendations for the diagnosis and management of hemophagocytic lymphohistiocytosis associated with malignancies. Haematologica 100: 997-1004, 2015.

8. Adachi E, Koibuchi T, Imai K, Kikuchi T, Shimizu S, Koga M, Nakamura H, Iwamoto A and Fujii T: Hemophagocytic syndrome in an acute human immunodeficiency virus infection. Intern Med 52: 629-632, 2013.

9. Meki A, O'Connor D, Roberts C and Murray J: Hemophagocytic lymphohistiocytosis in chronic lymphocytic leukemia. J Clin Oncol 29: e685-e687, 2011.

10. Usman M, Thapa SD, Hadid H and Yessayan LT: HIV infection presenting proliferation of CD8+ T lymphocyte and hemophagocytic lymphohistiocytosis. Int J STD AIDS 27: 411-413, 2016.

11. Uemura M, Huynh R, Kuo A, Antelo F, Deiss R and Yeh J: Hemophagocytic Lymphohistiocytosis complicating T-cell lymphoma in a patient with HIV infection. Case Rep Hematol 2013: 687260, 2013.

12. Tothova $Z$ and Berliner N: Hemophagocytic syndrome and critical Illness: New insights into diagnosis and management. J Intensive Care Med 30: 401-412, 2015.

13. Rouphael NG, Talati NJ, Vaughan C, Cunningham K, Moreira R and Gould C: Infections associated with haemophagocytic syndrome. Lancet Infect Dis 7: 814-822, 2007.

14. Janka G: Hemophagocytic lymphohistiocytosis: When the immune system runs amok. Klin Padiatr 221: 278-285, 2009. 